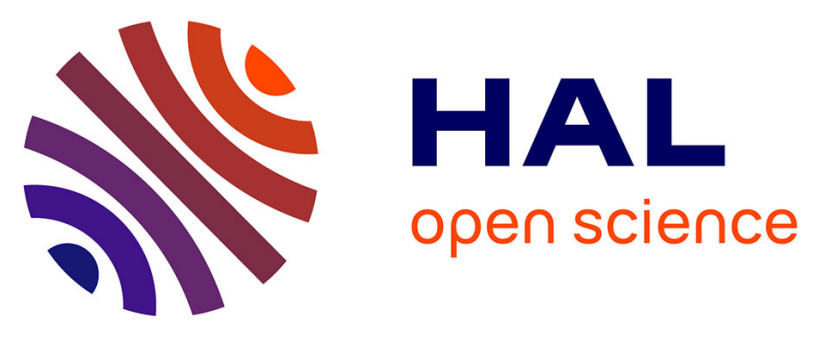

\title{
Tuning the catalytic activity and selectivity of water-soluble bimetallic RuPt nanoparticles by modifying their surface metal distribution
}

\author{
Donia Bouzouita, Guy Lippens, Edwin A Baquero, Pier-Francesco Fazzini, \\ Grégory Pieters, Yannick Coppel, Pierre Lecante, Simon Tricard, Luis Miguel \\ Martinez-Pietro, Bruno Chaudret
}

\section{To cite this version:}

Donia Bouzouita, Guy Lippens, Edwin A Baquero, Pier-Francesco Fazzini, Grégory Pieters, et al.. Tuning the catalytic activity and selectivity of water-soluble bimetallic RuPt nanoparticles by modifying their surface metal distribution. Nanoscale, 2019, 11 (35), pp.16544-16552. 10.1039/C9NR04149D . hal-02283913

\section{HAL Id: hal-02283913 \\ https://hal.science/hal-02283913}

Submitted on 24 Sep 2019

HAL is a multi-disciplinary open access archive for the deposit and dissemination of scientific research documents, whether they are published or not. The documents may come from teaching and research institutions in France or abroad, or from public or private research centers.
L'archive ouverte pluridisciplinaire HAL, est destinée au dépôt et à la diffusion de documents scientifiques de niveau recherche, publiés ou non, émanant des établissements d'enseignement et de recherche français ou étrangers, des laboratoires publics ou privés. 


\title{
Tuning the Catalytic Activity and Selectivity of
}

\section{Water-Soluble Bimetallic RuPt Nanoparticles by}

\section{Modifying their Surface Metal Distribution}

\author{
Donia Bouzouita, ${ }^{1}$ Guy Lippens, ${ }^{2}$ Edwin A. Baquero, ${ }^{3}$ Pier F. Fazzini,${ }^{1}$ Gregory Pieters,${ }^{4}$ \\ Yannick Coppel, ${ }^{5}$ Pierre Lecante, ${ }^{6}$ Simon Tricard, ${ }^{1, *}$ Luis M. Martínez-Prieto ${ }^{1, *}$ and Bruno
} Chaudret ${ }^{1, *}$

${ }^{1}$ LPCNO, Laboratoire de Physique et Chimie des Nano-Objets, INSA, CNRS, UPS, Université de Toulouse, 135, Avenue de Rangueil, F-31077 Toulouse, France..

${ }^{2}$ LISBP, Université de Toulouse, CNRS, INRA, INSA, UPS 135 avenue de Rangueil, F31077 Toulouse, France.

${ }^{3}$ Departamento de Química, Facultad de Ciencias Universidad Nacional de Colombia, Sede Bogotá Carrera 30 No. 45-03, 111321, Bogotá, Colombia.

${ }^{4}$ SCBM, CEA, Univ. Paris Saclay, F-91191, Gif-sur-Yvette, France.

${ }^{5}$ CNRS, LCC (Laboratoire de Chimie de Coordination), Université de Toulouse, UPS, INPT, 205 route de Narbonne, BP 44099, F-31077-Toulouse Cedex 4, France.

${ }^{6}$ CEMES (Centre d'Elaboration de Matériaux et d'Etudes Structurales), CNRS, 29 Rue J. Marvig, F-31055 Toulouse, France.

\begin{abstract}
$\underline{\text { Abstract }}$
Bimetalllic ruthenium-platinum nanoparticles (RuPt NPs) of different surface distributions and stabilized by a sulfonated N-heterocyclic carbene ligand (1-(2,6-diisopropylphenyl)-3-(3-potassium sulfonatopropyl)-imidazol-2-ylidene) were prepared from $\mathrm{Ru}(\mathrm{COD})(\mathrm{COT})$ (COD = cyclooctadiene and $\mathrm{COT}=$ cyclooctatriene), and platinum precursors displaying various decomposition rates $\left(\mathrm{Pt}(\mathrm{NBE})_{3}, \mathrm{NBE}=\right.$ norbornene, $\mathrm{Pt}\left(\mathrm{CH}_{3}\right)_{2}(\mathrm{COD})$ and $\mathrm{Pt}_{2}(\mathrm{DBA})_{3}, \mathrm{DBA}=$ dibenzylideneacetone $)$. Structural and surface studies by FT-IR and solid state MAS NMR, using carbon monoxide as a probe molecule, revealed for the different nanoparticles of similar sizes the presence of different structures and surface compositions, which principally depend on the decomposition rate of the organometallic precursors used during the synthesis. Specifically, the slower is the decomposition rate of the platinum
\end{abstract}


precursor, the higher is the number of Pt atoms at the NP surface. The different bimetallic RuPt NPs, as well as their monometallic equivalents ( $\mathrm{Pt}$ and $\mathrm{Ru} \mathrm{NPs}$ ), were used in isotopic H/D exchange through $\mathrm{C}-\mathrm{H}$ activation on L-lysine. Interestingly, the activity and selectivity of the direct $\mathrm{C}-\mathrm{H}$ deuteration were dependent upon the NP surface composition at the $\alpha$ position but not at the $\varepsilon$ one. Chemical shift perturbation (CSPs) experiments revealed that the difference of reactivity at the $\alpha$ position is due to a Pt-carboxylate interaction, which hinders the H/D exchange.

\section{Introduction}

Bimetallic nanoparticles (NPs) have attracted a great interest in many scientific areas, particularly in catalysis where these materials have shown interesting properties. ${ }^{1}$ Over the years, a great number of systems have been studied with, inter alia, the aim to control the chemical order at small size for tuning both the physical and the chemical properties of the resulting particles. Thus, years ago, we studied the progressive incorporation of ruthenium into platinum NPs, leading to alloy particles of small size $(<2 \mathrm{~nm})$ which retained the crystal structure of the corresponding bulk alloys. When the $\mathrm{Pt}$ content is high, the bimetallic NPs adopt the face-centered cubic (fcc) structure, while for high Ru contents the structure changes to hexagonal close-packed (hcp). ${ }^{2}$ Following this research line, small core-shell RuPt NPs stabilized by polyvinylpyrrolidone (PVP) were obtained by co-decomposition under a hydrogen atmosphere of $\mathrm{Ru}(\mathrm{COD})(\mathrm{COT}), \mathrm{COD}=$ cyclooctadiene and $\mathrm{COT}=$ cyclooctatriene, and $\operatorname{Pt}\left(\mathrm{CH}_{3}\right)_{2}(\mathrm{COD})$ at room temperature. ${ }^{3}$ However, when the decomposition of a mixture of $\mathrm{Ru}(\mathrm{COD})(\mathrm{COT})$ and $\mathrm{Pt}\left(\mathrm{CH}_{3}\right)_{2}(\mathrm{COD})$ was performed in the presence of 1,4Bis(diphenylphosphino)butane (dppb), the resulting bimetallic NPs presented a ruthenium rich core and a disordered shell containing both ruthenium and platinum, probably due to the high chemical affinity of the diphosphine ligand for both metals. Such a change in surface composition then explained the change in the reactivity of the NPs. ${ }^{4}$ This observation demonstrates the potential of molecular chemistry in the synthesis of nanoparticles, being able to modulate their structures, their surface composition and thus their corresponding catalytic properties.

N-Heterocyclic carbenes (NHCs) are excellent ligands to stabilize metal nanoparticles (MNPs) due to their high electron donor capacity. ${ }^{5}$ As they form strong ligand-transition metal bonds, they are more

\footnotetext{
1 a) T. Chen, V.O. Rodionov, ACS Catal. 2016, 6, 4025. b) M. Sankar, N. Dimitratos, P.J. Miedziak, P.P. Wells, C.J. Kiely, G.J. Hutchings, Chem. Soc. Rev., 2012, 41, 8099. c) Bimetallic Nanostructures: Shape-Controlled Synthesis for Catalysis, Pasmonics and sensing applications, Ed. Y-W. Zhang, Wiley-VCH, Weinheim, 2018.

2 a) Pan, C.; Dassenoy, F.; Casanove, M. J.; Philippot, K.; Amiens, C.; Lecante, P.; Mosset, A.; Chaudret, B. J. Phys. Chem. B 1999, 103, 10098. Dassenoy, F.; Casanove, M. J.; Lecante, P.; Pan, C.; Philippot, K.; Amiens, C.; Chaudret, B. Phys. Rev. B 2001, 63, 235407.

${ }^{3}$ Lara, P.; Casanove, M.-J.; Lecante, P.; Fazzini, P.-F.; Philippot, K.; Chaudret, B. J. Mat. Chem. 2012, 22, 3578-3584.

${ }^{4}$ Lara, P.; Ayval, T.; Casanove, M.-J.; Lecante, P.; Mayoral, A.; Fazzini, P.-F.; Philippot, K.; Chaudret, B. Dalton Trans. 2013, 42, 372.

${ }^{5}$ M. N. Hopkinson, C. Richter, M. Schedler, F. Glorius, Nature 2014, 510, 485-496.
} 
and more used as stabilizer of MNPs $^{6}$ and metal-surfaces ${ }^{7}$. Moreover, introducing a sulfonate group into the N-substituent makes the NHC-stabilized MNPs soluble in water, as recently reported for monometallic Pt, Ru and Pd NPs. ${ }^{8}$

Hydrogen isotope exchange (HIE) is considered as a methodology of choice for the synthesis of deuterium-labeled compounds, which are, for example, extensively employed in the pharmaceutical industry to enhance the efficiency and safety of a drug. Deuterated substrates are also broadly used as mass spectrometry standards, or for mechanistic studies in organic and organometallic chemistry. ${ }^{9}$ The direct $\mathrm{C}-\mathrm{H}$ deuteration using transition metal catalysts has been widely investigated by both homogeneous ${ }^{10}$ and heterogeneous catalysis. ${ }^{11}$ Some of us have recently reported the use of Ru NPs for the selective deuteration of several nitrogen and sulfur containing bioactive compounds..$^{12}$ The deuteration of pyridines, quinolines, indoles, alkyl amines and thioethers was highly selective to the $\alpha$ position of nitrogen or sulfur atoms. Such a procedure was extended to a large diversity of amino

\footnotetext{
${ }^{6}$ For NHCs as ligands for unsupported NPs see for example: a) J. Vignolle, T. D. Tilley, Chem. Commun. 2009, 7230. b) P. Lara, O. Rivada-Wheelaghan, S. Conejero, R. Poteau, K. Philippot, B. Chaudret, Angew. Chem. Int Ed. 2011, 50, 12080; c) L. M. Martínez-Prieto, A. Ferry, P. Lara, C. Richter, K. Philippot, F. Glorius, B. Chaudret, Chem. Eur. J, 2015, 21, 17495; d) L. M. Martínez-Prieto, A. Ferry, L. Rakers, C. Richter, P. Lecante, K. Philippot, B. Chaudret, F. Glorius, Chem. Commun. 2016, 52, 4768; e) P. Lara, L. M. Martínez-Prieto, M. Roselló-Merino, C. Richter, F. Glorius, S. Conejero, K. Philippot, B. Chaudret, NanoSO 2016, 6, 39. f) L. Rakers, L. M. Martínez-Prieto, A. M. López-Vinasco, K. Philippot, P. W. N. M. van Leeuwen, B. Chaudret, F. Glorius, Chem. Commun. 2018, 54, 7070. For NHCs on supported metal NPs, see: g) K. V. S. Ranganath, J. Kloesges, A. H. Schäfer, F. Glorius, Angew. Chem. Int. Ed. 2010, 49, 7786; h) K. V. S. Ranganath, A. Schäfer, F. Glorius, ChemCatChem. 2011, 3, 1889; i) D. Yu, M. X. Tan and Y. Zhang, Adv. Synth. Catal. 2012, 354, 969.

${ }^{7}$ For NHCs on metal surfaces, see: a) T. Weidner, N. Ballav, U. Siemeling, D. Troegel, T. Walter, R. Tacke, D. G. Castner, M. Zharnikov, J. Phys. Chem. C. Nanomater. Interfaces 2009, 113, 19609; b) T. Weidner, J: E. Baio, A. Mundstock, C. Große, S. Karthäuser, C. Bruhn, U. Siemeling, Aust. J. Chem. 2011, 64, 1177; c) A. V. Zhukhovitskiy, M. G. Mavros, T. V. Voorhis, J. A. Johnson, J. Am. Chem. Soc. 2013, 135, 7418; d) C. M. Crudden, J. H. Horton, I. I. Ebralidze, O. V. Zenkina, A. B. McLean, B. Drevniok, Z. She, H.-B. Kraatz, N. J. Mosey, T. Seki, E. C. Keske, J. D. Leake, A. Rousina-Webb, G. Wu, Nature Chem. 2014, 6, 409.
}

8 a) E. A. Baquero, S. Tricard, J. C. Flores, E. de Jesús, B. Chaudret, Angew. Chem. Int. Ed. 2014, 53, 13220; b) J. M. Asensio, S. Tricard, Y. Coppel, R. Andrés, B. Chaudret, E. de Jesús, Angew. Chem. Int. Ed. 2017, 56, 865; c) L. M. Martínez-Prieto, E. A. Baquero, G. Pieters, J. C. Flores, E. de Jesús, C. Nayral, F. Delpech, P. W. N. M. van Leeuwen, G. Lippens, B. Chaudret, Chem. Commun. 2017, 53, 5850.

${ }^{9}$ a) J. Atzrodt, V. Derdau, W. J. Kerr, M. Reid, Angew. Chem. Int. Ed. 2018, 57, 1758; b) J. Atzrodt, V. Derdau, W. J. Kerr, M. Reid, Angew. Chem. Int. Ed. 2018, 57, 3022.

10 a) S. R. Klei, J. T. Golden, T. D. Tilley, R. G. Bergman, J. Am. Chem. Soc. 2002, 124, 2092; b) J. T. Golden, R. A. Andersen, R. G. Bergman, J. Am. Chem. Soc. 2001, 123, 5837; c) V. M. lluc, A. Fedorov, R. H. Grubbs, Organometallics 2012, 31, 39; d) S. K. Hanson, D. M. Heinekey, K. I. Goldberg, Organometallics 2008, 27,1454; e) C. M. Yung, M. B. Skaddan, R. G. Bergman, J. Am. Chem. Soc. 2004, 126, 13033; I) B. Rybtchinski, R. Cohen, Y. Ben-David, J. M. L. Martin, D. Milstein, J. Am. Chem. Soc. 2003, 125, 11041; f) J. Zhou, J. F. Hartwig, Angew. Chem. Int. Ed. 2008, 47, 5783. g) L. Piola, J. A. Fernandez-Salas, S. Manzini, S. P. Nolan, Org. Biomol. Chem. 2014, 12, 8683; h) L. Neubert, D. Michalik, S. Baehn, S. Imm, H. Neumann, J. Atzrodt, V. Derdau, W. Holla, M. Beller, J. Am. Chem. Soc. 2012, 134, 12239; i) L. V. A. Hale, N. K. Szymczak, J. Am. Chem. Soc. 2016, 138, 13489; j) J. Campos, A. C. Esqueda, J. López-Serrano, L. Sánchez, F. P Cossio, A. De Cozar, E. Álvarez, C. Maya, E. Carmona J. Am. Chem. Soc., 2010, 132, 16765.

11 a) T. Maegawa, Y. Fujiwara, Y. Inagaki, H. Esaki, Y. Monguchi, H. Sajiki, Angew. Chem. Int. Ed. 2008, 47, 5394.b) Y. Fujiwara, H. Iwata, Y. Sawama, Y. Monguchi, H. Sajiki, Chem. Commun. 2010, 46, 4977; c) K. A. Guy, J. R. Shapley, Organometallics 2009, 28, 4020; d) E. Breso-Femenia, C. Godard, C. Claver, B. Chaudret, S. Castillon, Chem. Commun. 2015, 51, 16342; f) H. Esaki, F. Aoki, M. Umemura, M. Kato, T. Maegawa, Y. Monguchi, H.Sajiki, Chem. Eur. J. 2007, 13, 4052; g) Y. Sawama, Y. Yabe, H. Iwata, Y. Fujiwara, Y. Monguchi, H. Sajiki, Chem. Eur. J. 2012, 18, 16436; h) H. Sajiki, T. Kurita, H. Esaki, F. Aoki, T. Maegawa, K. Hirota, Org. Lett. 2004, 6, 3521; i) T. Mutsumi, H. Iwata, K. Maruhashi, Y. Monguchi, H. Sajiki, Tetrahedron 2011, 67, 1158; j) V. Derdau, J. Atzrodt, J. Zimmermann, C. Kroll, F. Brückner, Chem. Eur. J. 2009, 15, 10397.

12 a) G. Pieters, C. Taglang, E. Bonnefille, T. Gutmann, C. Puente, J.-C. Berthet,C. Dugave, B. Chaudret, B. Rousseau, Angew. Chem. Int. Ed. 2014, 53, 230. b) L. Gao, S. Perato, S. Garcia-Argote, C. Taglang, L. M. Martinez-Prieto, C. Chollet, D.-A. Buisson, V. Dauvois, P. Lesot, B. Chaudret, B. Rousseau, S. Feuillastre, G. Pieters, Chem. Commun. 2018, 54, 2986-2989. 
acids, peptides and marketed drugs, and was found to be enantiospecific with full retention of the configuration. ${ }^{12 b, 13}$ Lastly, water-soluble NHC-stabilized Ru NPs were successfully applied in catalytic $\mathrm{C}-\mathrm{H}$ deuteration of L-lysine, with a regioselectivity depending on the $\mathrm{pH}$ of the solution ${ }^{8 \mathrm{c}}$ However, bio-compounds in physiological environment do not allow extreme $\mathrm{pH}$ variations, motivating us to develop ways of controlling the selectivity by tuning the catalyst nature rather than the external environment. Bimetallic RuPtNPs were synthesized in such a purpose and we found that they were stable in water, active for deuteration, and that they induced different selectivities, arising from different platinum precursors $\left(\mathrm{Pt}(\mathrm{NBE})_{3}, \mathrm{NBE}=\right.$ norbornene, $\mathrm{Pt}\left(\mathrm{CH}_{3}\right)_{2}(\mathrm{COD}), \quad \mathrm{COD}=1,5$ cyclooctadiene, and $\mathrm{Pt}_{2}(\mathrm{DBA})_{3}, \mathrm{DBA}=$ dibenzylideneacetone). This behavior, rationalized by WAXS, FT-IR, solid state NMR measurements and by chemical shift perturbation studies, was explained by a modulation of the NP surface composition. This work thus allowed us to gain a better understanding of the substrate/nanoparticle interaction in $\mathrm{C}-\mathrm{H}$ activation reactions.

\section{$\underline{\text { Results and discussion }}$}

\section{Synthesis, and nanoparticle characterization.}

Bimetallic and monometallic water-soluble NPs were prepared by decomposition of the corresponding organometallic precursors in THF at room temperature (r.t.) under $\mathrm{H}_{2}$ pressure (3 bars) and in the presence of 0.25 equiv. of a sulfonated NHC, namely 1-(2,6-diisopropylphenyl)-3-(3-potassium sulfonatopropyl)-imidazol-2-ylidene (Scheme 1). Monometallic Ru (Ru) and Pt NPs (Pt) were prepared using $\mathrm{Ru}(\mathrm{COD})(\mathrm{COT})$ and $\mathrm{Pt}(\mathrm{NBE})_{3}$ respectively, following a previously reported synthetic procedure. ${ }^{6 c-f, 14}$ In addition, four bimetallic systems were obtained after co-decomposition of $\mathrm{Ru}(\mathrm{COD})(\mathrm{COT})$ and the $\mathrm{Pt}$ organometallic precursor. Three different precursors were chosen as a function of their ease of decomposition under $\mathrm{H}_{2}$, namely $\mathrm{Pt}(\mathrm{NBE})_{3}$, $\left[\mathrm{Pt}\left(\mathrm{CH}_{3}\right)_{2}(\mathrm{COD})\right]$ and $\mathrm{Pt}_{2}(\mathrm{DBA})_{3}$, giving rise respectively to RuPt-nor, RuPt-DMC (DMC stands for dimethyl cyclooctadiene) and RuPt-dba in a 1:1 molar ratio. $\mathrm{Pt}_{2}(\mathrm{dba})_{3}$ was also used in a 1:2 Ru:Pt molar ratio, and gave $\mathbf{R u P t}_{2^{-}}$ dba. This strategy leads to water-soluble systems where the surface state of bimetallic nanoparticles can be modulated. The water-soluble NHC-stabilized mono and bimetallic NPs were obtained as a black powder after purification by washing with pentane. The powder can be stored in a glovebox and keeps its catalytic properties for at least one year.

\footnotetext{
${ }^{13}$ a) C. Taglang, L. M. Martínez-Prieto, I. del Rosal, L. Maron, R. Poteau, K. Philippot, B. Chaudret, S. Perato, A. Sam Lone, C. Puente, G. Pieters, Angew. Chem. Int. Ed. 2015, 54, 10474.

${ }^{14}$ a) L. M. Martínez-Prieto, I. Cano, A. Márquez, E. A. Baquero, S. Tricard, L. Cusinato, I. del Rosal, R. Poteau, Y. Coppel, K. Philippot, B. Chaudret, J. Cámpora, P. W. N. M van Leeuwen, Chem. Sci. 2017, 8, 2931.
} 

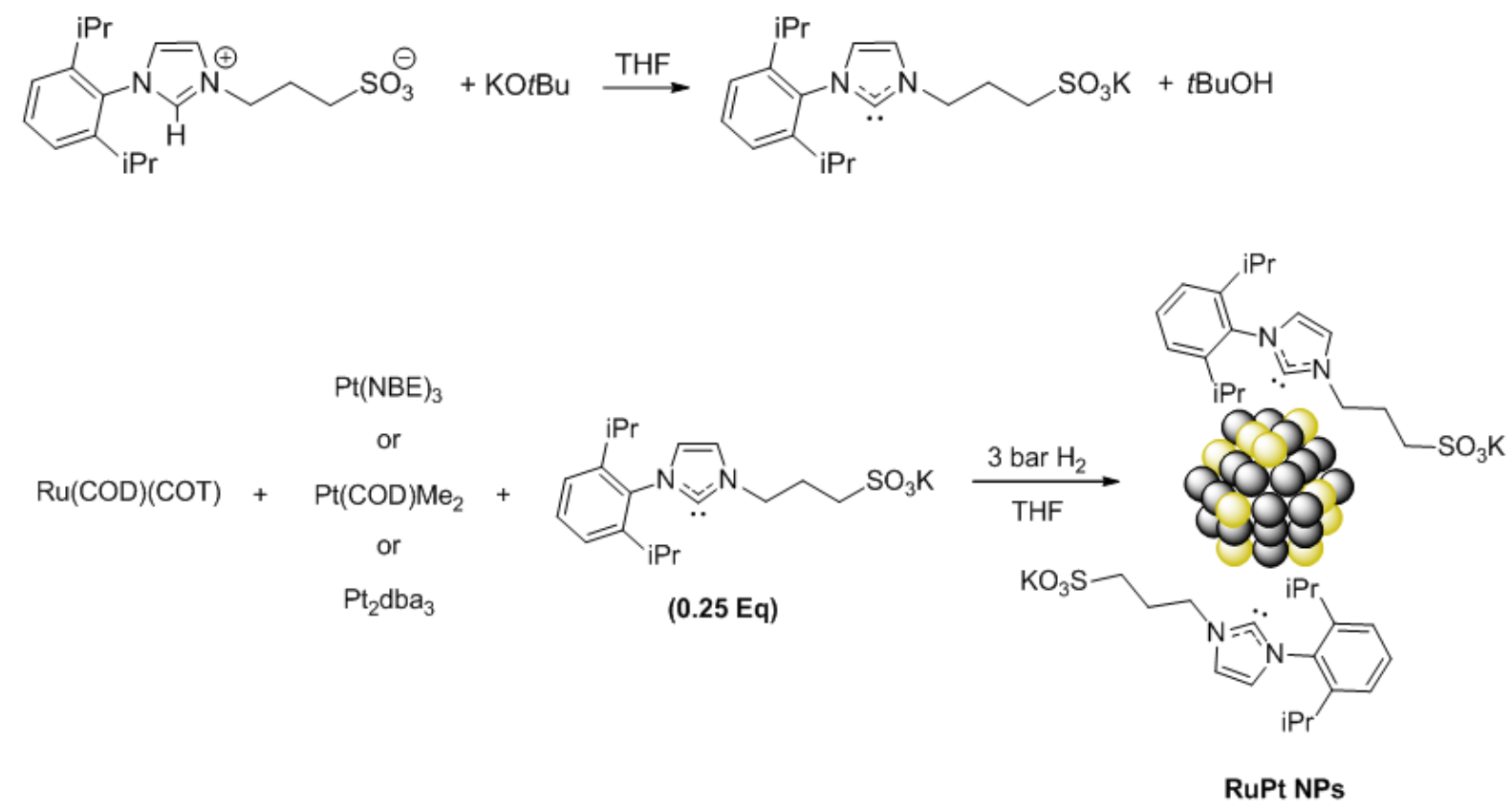

Scheme 1. Synthesis of Ru, Pt, RuPt-nor, RuPt-DMC, RuPt-dba and RuPt $\mathbf{2}_{2}$-dba.

Transmission electron microscopy (TEM) analyses of the reference Ru and Pt NPs present NPs of 1.3 (0.3) and 1.5 (0.4) nm respectively, as observed in Figure 1a and b. The bimetallic systems RuPt-nor, RuPt-DMC, RuPt-dba and $\mathbf{R u P t}_{2}$-dba revealed the presence of spherical, well-distributed and monodispersed NPs of similar sizes with a mean diameter of $1.5(0.4), 1.4(0.3), 1.3(0.4)$ and $1.3(0.4)$ $\mathrm{nm}$ respectively (Figure $1 \mathrm{c}$ to $\mathrm{f}$ ). 

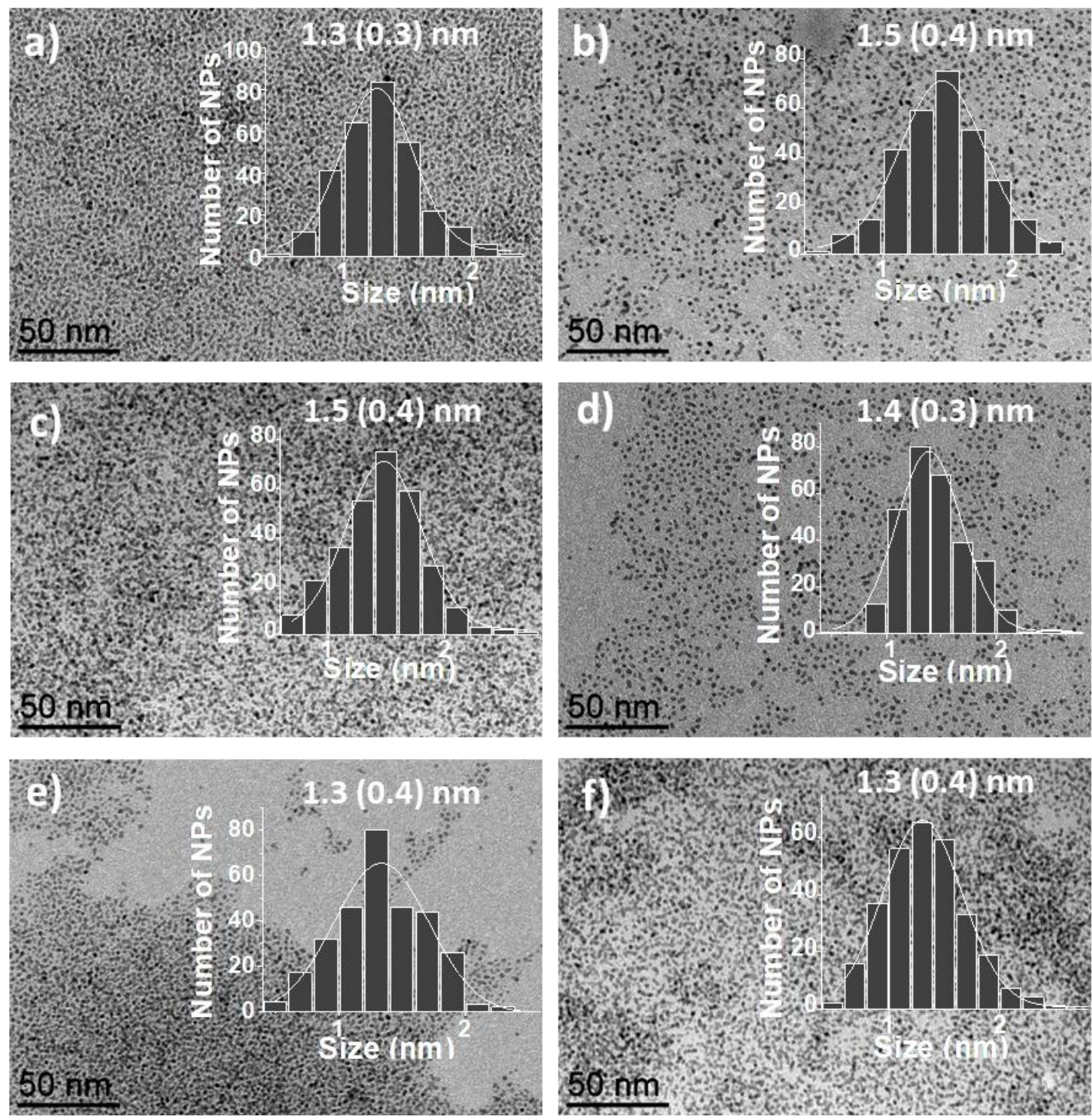

Figure 1. TEM micrographs and the corresponding size histograms of a) Ru, b) Pt, c) RuPt-nor, d) RuPt-DMC, e) RuPt-dba and f) RuPt $\mathbf{2}_{2}$-dba NPs.

High resolution TEM (HRTEM) analyses confirmed the crystallinity of RuPt-nor, RuPt-DMC and $\mathbf{R u P t}_{2}$-dba (Figures S1-S3). Scanning electron microscopy coupled with energy-dispersive X-ray spectroscopy (SEM-EDX) showed a homogenous distribution of Ru and $\mathrm{Pt}$ at the micron scale, with expected atomic ratios Ru:Pt close to 1:1 for RuPt-nor, RuPt-DMC and RuPt-dba, and close to 1:2 for $\mathbf{R u P t}_{2}$-dba (Figures S4-S7).

High Resolution STEM in bright field (BF) and high-angle annular dark-field (HAADF), obtained with an atomic resolution microscope (ARM), of RuPt-nor and RuPt-DMC showed small, spherical and crystalline NPs (Figures 2 and 3). Energy-dispersive X-ray spectroscopy (EDX) confirmed the presence of Pt-Ru alloy NPs (Pt:Ru 50\%:50\% = 1:1) for both RuPt-nor and RuPt-DMC. 


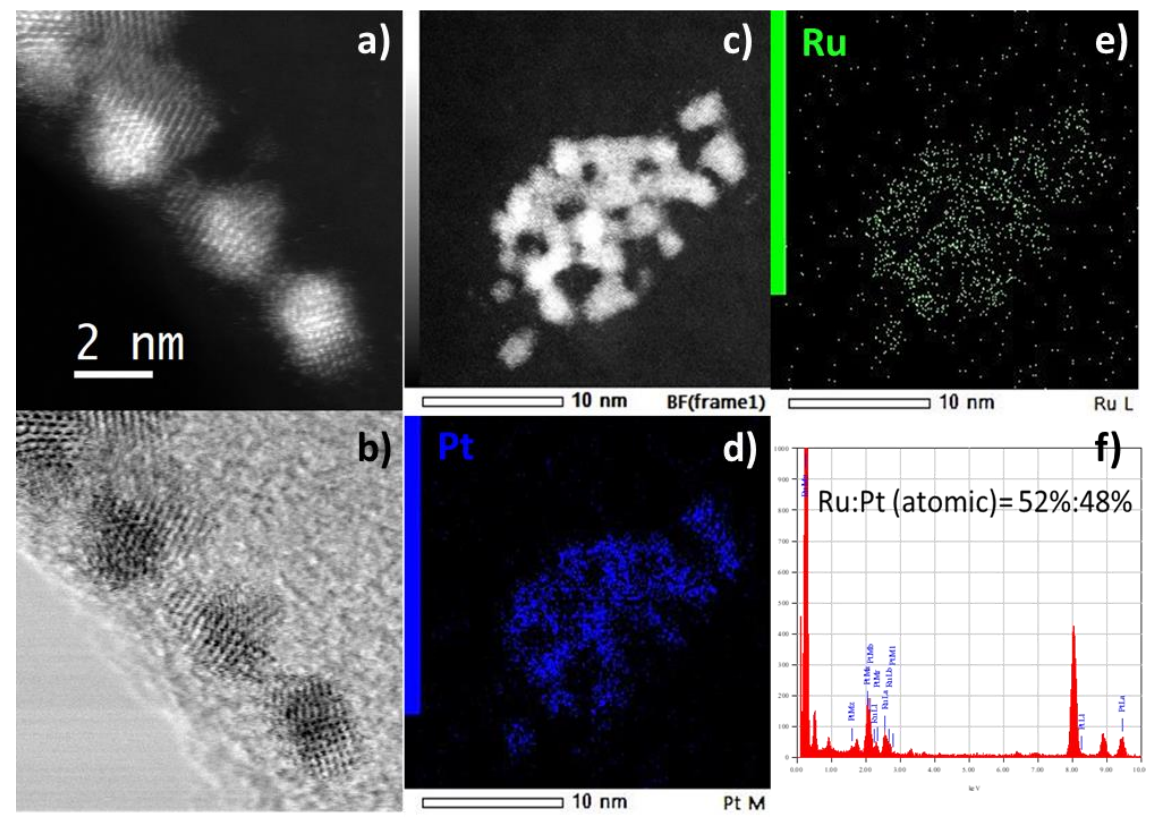

Figure 2. High Resolution (a) STEM, (b) HADDF and (c) BF images of RuPt-nor. (d, e) Elemental mapping and (f) relative composition of RuPt-nor as determined by EDX.
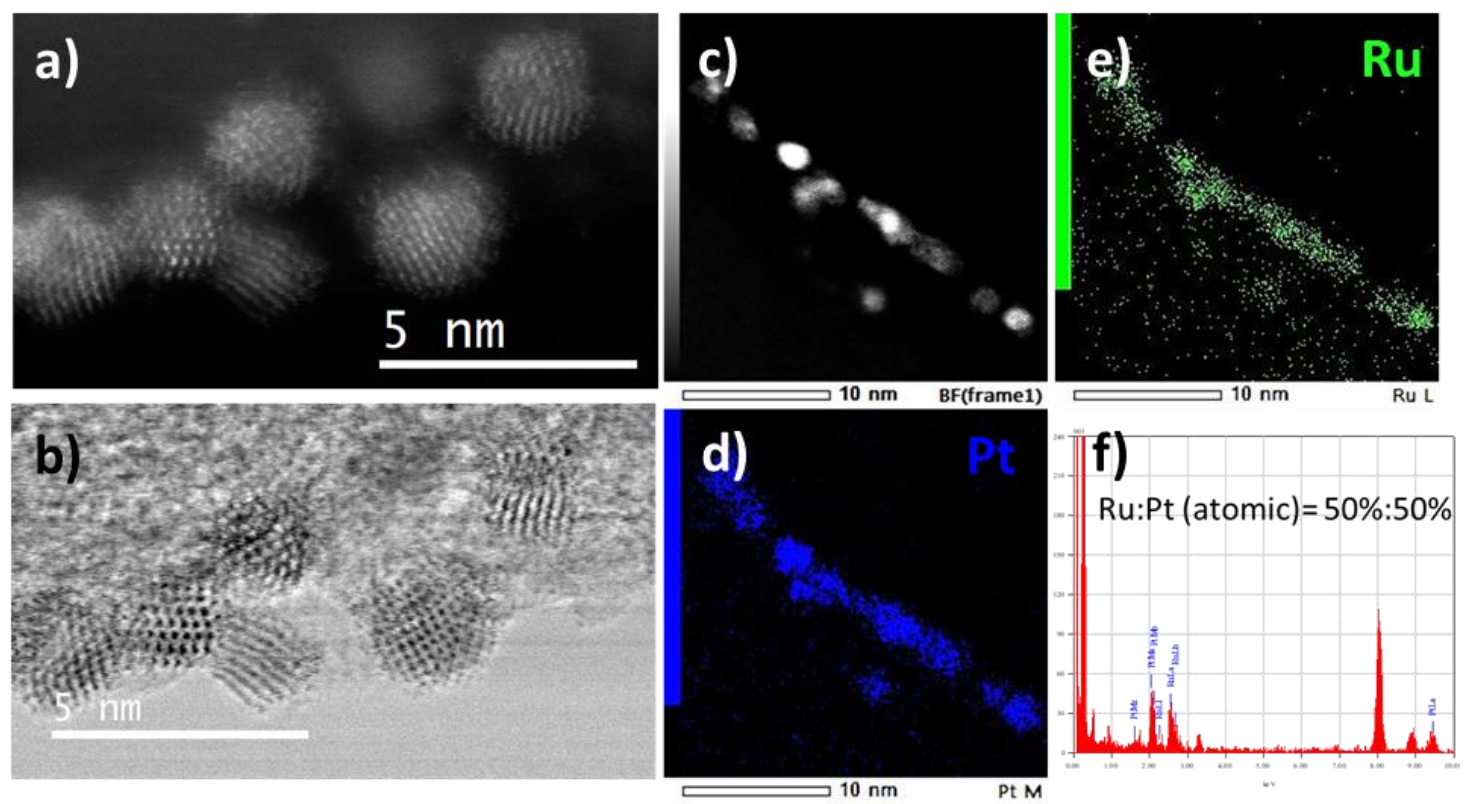

Figure 3. High Resolution (a) STEM (b) -HADDF and (c) -BF images of RuPt-DMC. (d-e) Elemental mapping (f) and relative composition of RuPt-DMC determined by EDX.

In addition to local probe studies, Wide-Angle X-ray Scattering (WAXS) analyses were performed to access global structural information. The monometallic NPs were comparable to the ones observed on monometallic $\mathbf{R} \mathbf{u}^{8 c}$ and Pt NPs using the same ligand. Specifically, Ru adopts the hexagonal closed 
packed (hcp) structure with a coherence length close to $1.6 \mathrm{~nm}$ and $\mathbf{P t}$ adopts the fcc structure with a coherence length close to $2.2 \mathrm{~nm}$ (Figure S8, top and bottom). Limited discrepancy between TEM size and WAXS coherence length has often been observed and is usually related to different weighting schemes for the different techniques. More surprisingly, the bimetallic samples display very different patterns ranging from fcc-like for RuPt-dba and $\mathbf{R u P t}_{2}$-dba to hcp-like for RuPt-DMC, the case of RuPt-nor being intermediate. The complete series of RDFs is similar to those obtained for an extended range of $\mathrm{Pt} / \mathrm{Ru}$ compositions. ${ }^{2 b}$ Since for a 1:1 RuPt alloy we expect a fcc structure, these results point to the formation of an alloy (i.e. a homogeneous distribution of the two metals) for RuPtdba and $\mathbf{R u P t}_{2}$-dba, and an anisotropic metal distribution in the other cases. Thus, deviation from the structure expected for a given composition has been observed by WAXS in several occurrences and has been related to core-shell segregation in the nanoparticles ${ }^{3,4,15}$ In all cases, the apparent structure reflects the order in the best crystallized part of the particle, obviously the core. This is therefore an indirect but global proof of Ru-enrichment of the core of RuPt-DMC, and thus of a Pt-enrichment of the shell (as confirmed below).

\section{Surface studies}

The surface state of the bimetallic RuPt NPs was characterized by attenuated total reflectance Fourier transform infrared (ATR FT-IR) and magic angle spinning solid-state NMR (MAS-NMR) measurements. Carbon monoxide (CO) coordinates easily on the Ru and Pt surface and displays a distinct signature according to its coordination mode and to the nature of the metal. It is thus possible to determine the presence of accessible sites and to get insight into the metal composition of the NP surface after $\mathrm{CO}$ adsorption. In both metals $(\mathrm{Pt}$ and $\mathrm{Ru}), \mathrm{CO}$ can coordinate in a bridging $(\mathrm{CO} b$; on the faces of the NP) or in a terminal mode (COt; on the apexes and edges of the NP), ${ }^{16}$ Figures S9-S14 show the FT-IR spectra of Ru, Pt, RuPt-nor, RuPt-DMC, RuPt-dba and $\mathbf{R u P t}_{2}$-dba NPs before (orange) and after (blue) $\mathrm{CO}$ adsorption (1 bar, r.t., $20 \mathrm{~h}$ ). In general, after exposure to $\mathrm{CO}$ all the spectra exhibit the characteristic absorption bands of $\mathrm{CO} b\left(\sim 1800 \mathrm{~cm}^{-1}\right)$ and $\mathrm{CO} t\left(\sim 2000 \mathrm{~cm}^{-1}\right)$. Comparing the spectra in the $1800-2200 \mathrm{~cm}^{-1}$ region (Figure 4), we observe that for $\mathbf{R u}$ the frequency for the main contribution of $\mathrm{CO} t$ is $1965 \mathrm{~cm}^{-1}$ while for $\mathbf{P t}$ it is $2034 \mathrm{~cm}^{-1}$. As this main contribution of CO $t$ absorptions for RuPt-nor, RuPt-dba, RuPt $\mathbf{2}_{2}$-dba and RuPt-DMC appear at 2003, 2005, 2024 and $2026 \mathrm{~cm}^{-1}$, respectively, we can propose that $\mathbf{R u P t}_{2}-\mathbf{d b a}$ and $\mathbf{R u P t}-\mathbf{D M C}$ displays a Pt rich surface, whereas an alloy type surface is expected for RuPt-nor and RuPt-dba. We can thus find some differences at the surface, an enrichment of Pt being observed as we advance in the sequence

\footnotetext{
${ }^{15}$ a) C. Bergounhou, C. Blandy, R. Choukroun, P. Lecante, C. Lorbera, J.-L. Pellegatta, New J. Chem., 2007, 31, 218-223. b) V. Kelsen, A. Meffre, P.-F. Fazzini, P. Lecante, B. Chaudret, ChemCatChem 2014, 6, $1714-1720$

${ }^{16}$ a) F. Novio, K. Philippot, B. Chaudret, Catal. Lett. 2010, 140, 1. b) E. Ramírez, L. Eradés, K. Philippot, P. Lecante, B. Chaudret Adv. Funct. Mat. 2007, 17, 2219.
} 
RuPt-nor $\approx$ RuPt-dba $<<$ RuPt-DMC $\approx \mathbf{R u P t}_{2}$-dba. This series confirms that very different surfaces can be obtained by changing only the organometallic precursor used during the synthesis. The higher concentration of Pt atoms on the surface of RuPt-DMC results from the slow decomposition of the PtDMC precursor, which is assisted by ruthenium and leads to an enrichment in Pt on the shell of the NP. ${ }^{3} \mathbf{R u P t}_{2}$-dba has been proven to be a fcc alloy, but also presents a high percentage of Pt atoms on its surface, as expected from its chemical composition. RuPt-nor and RuPt-dba display similar surfaces in terms of $\mathrm{Ru}$ and $\mathrm{Pt}$ concentrations, as shown by similar frequencies for the main contribution of $\mathrm{CO} t$, intermediate between the ones of $\mathbf{P t}$ and those of $\mathbf{R u}$. Therefore, we can modulate the surface composition of bimetallic RuPt NPs prepared by the organometallic approach via two ways: i) the decomposition rate of the organometallic precursors used in the synthesis and ii) the molar stoichiometry of these organometallic precursors (1:1, 1:2, etc.).

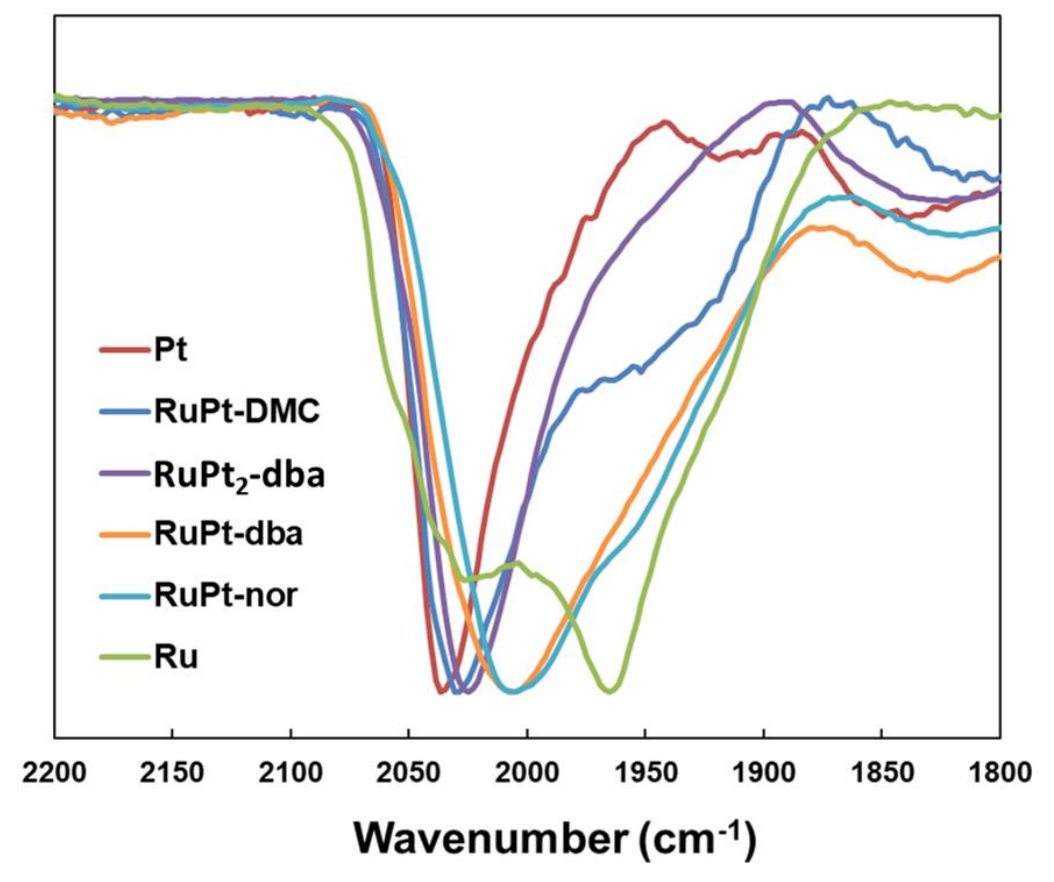

Figure 4. Normalized ATR FT-IR spectra of Pt (red), RuPt-DMC (dark blue), RuPt $\mathbf{t}_{2}$-dba (purple), RuPt-dba (orange), RuPt-nor (light blue) and Ru (green) after CO adsorption.

A small CO absorption band for Ru (Figure S9), RuPt-nor, RuPt-dba and RuPt-DMC (Figures S11S14) is visible on FT-IR spectra before exposure to carbon monoxide (orange). This behaviour is typical for Ru NPs, which are able to decarbonylate THF used as solvent during the NP synthesis. ${ }^{17}$ This decarbonylation process has never been observed for Pt NPs, and consequently no CO band before reaction of Pt NPs with carbon monoxide could be detected (Figure S10). Interestingly, bimetallic $\mathbf{R u P t}_{2}$-dba NPs are not able to decarbonylate THF either, which supports the enrichment of their surface in Pt atoms.

\footnotetext{
${ }^{17}$ L. M. Martínez-Prieto, C. Urbaneja, P. Palma, J. Campora, K. Philippot, B. Chaudret, Chem. Comm. 2015, 51, 4647
} 
The presence of the water-soluble carbene on the NP surface was also demonstrated by solid-state ${ }^{13} \mathrm{C}$ CP-MAS NMR spectra of Ru, Pt, RuPt-nor, RuPt-DMC, RuPt-dba and RuPt ${ }_{2}$-dba (Figures S15S20). In all spectra, we can find all the signals of the sulfonated NHC ligand on the NP. The signals are assigned to: $\sim 163$ ppm: imidazolium carbene carbon ; 142 ppm: quaternary carbons of aromatic ring; 125-122 ppm: protonated carbons of aromatic ring and imidazolium backbone; 47 ppm: $\alpha$ and $\gamma$ alkyl chain $\mathrm{CH}_{2}$ groups of the sulfonated N-substituent; 25-22 ppm: isopropyl and $\beta$ alkyl chain $\mathrm{CH}_{2}$ groups, as previously demonstrated..$^{\mathrm{a}, \mathrm{c}}$

After submitting all the nanoparticle samples to a pressure of 1 bar of ${ }^{13} \mathrm{CO}$ (r.t., 20 h), their ${ }^{13} \mathrm{C}$ MAS NMR spectra (Figures S21-S26) display intense and broad high frequency resonances corresponding to adsorbed ${ }^{13} \mathrm{CO}$. For monometallic Ru NPs, a broad signal corresponding to bridging $\mathrm{CO}(\mathrm{CO} b)$ is visible at $232 \mathrm{ppm}$, on which is superimposed a peak corresponding to terminal $\mathrm{CO}(\mathrm{CO} t)$ at $198 \mathrm{ppm}$ (Figure S21). As commonly observed in other Ru NPs systems, the $\mathrm{CO} t$ showed a more intense signal than $\mathrm{CO} b$ in ${ }^{13} \mathrm{C}$ CP-MAS experiment, notably due to a difference of surface mobility. ${ }^{15 a, 18}$ In contrast, for monometallic Pt NPs, very broad peaks between 200-500 ppm are observed for $\mathrm{CO} b / \mathrm{CO} t$ resonances, experiencing weak to strong Knight shifts (as the NPs stands here in the critical size where Knight shift effects appear). ${ }^{19}$ Similar chemical shifts have been previously observed on platinum NPs of similar size. ${ }^{14}$ No CO signal could be observed in the ${ }^{13} \mathrm{C}$ CP-MAS experiment due to their fast relaxation. All bimetallic RuPt systems display two very broad resonances centered near 220-240 ppm and 330-370 ppm for the major and the minor ones, respectively (Figures S23 - S26). These signals correspond to the superimposition of $\mathrm{Ru} \mathrm{CO} b$ and Knight shifted $\mathrm{Pt} \mathrm{CO} b / \mathrm{CO} t$ resonances. The width of these resonances presumably results from the presence of different chemical environment and coordination modes either on Ru or on Pt. The proportion of Knight shifted Pt COb/COt signal (versus total CO signal) increase in the sequence RuPt-dba $(25 \pm 5 \%)<$ RuPt-nor $(31 \pm 5 \%)<$ RuPt-DMC $(35 \pm 5 \%)<\mathbf{R u P t}_{2}-\mathbf{d b a}(44 \pm 5 \%)$. This series, in addition to the descriptions of the WAXS and FT-IR experiments, gives the following surface compositions: an alloy surface for RuPt-dba, a Pt rich surface for RuPt-DMC, an intermediate situation for RuPt-nor and a Pt rich alloy for $\mathbf{R u P t}_{2}$-dba. In ${ }^{13} \mathrm{C}$ CP-MAS experiment, weak diamagnetic Ru CO $t$ resonances were observed only for RuPt-dba and $\mathbf{R u P t}_{2}$-dba, with an additional diamagnetic broad $\mathrm{Ru} \mathrm{CO} b$ resonance for RuPt-dba. This observation can be due in part to the relative smaller size of RuPt-dba and $\mathbf{R u P t}_{\mathbf{2}}$-dba NP sample (mean diameter of $1.3(0.4) \mathrm{nm}$ ), in which very small NPs can exhibit the diamagnetic CO resonances. The higher proportion of Knight shifted Pt COb/COt in $\mathbf{R u P t}_{2}-\mathbf{d b a}$ NPs (Figure S26) confirms the presence of a higher concentration of surface $\mathrm{Pt}$ in these nanoparticles. Furthermore, the weaker Knight shift effect observed in the bimetallic $\mathrm{Ru}: \mathrm{Pt}=1: 1 \mathrm{NPs}$ compared to the monometallic Pt NPs

\footnotetext{
${ }^{18}$ L.M. Martínez-Prieto, B. Chaudret, Acc. Chem. Res., 2018, 51 376-384.

19 J.M. Asensio, S. Tricard, Y. Coppel, R. Andrés, B. Chaudret, E. de Jesús, Angew. Chem. Int. ed. 2017, 129, 883887.
} 
shows : i) that the structure of particles is not homogeneous and ii) that the presence of ruthenium limits the development of magnetism in the particles as it does when it is alloyed to ferromagnetic materials.

\section{Catalytic Studies.}

The catalytic activity of the water-soluble RuPt NPs was studied in the deuteration of L-lysine in order to compare all the systems. Deuteration reactions were carried out using a catalytic loading of 6-7 \% of NPs in $\mathrm{D}_{2} \mathrm{O}$ under 2 bars of $\mathrm{D}_{2}$ at $55^{\circ} \mathrm{C}$ for 42 hours. Deuteration reactions were carried out by submitting a solution of lysine to 2 bars $\mathrm{D}_{2}$ at $55^{\circ} \mathrm{C}$ for 42 hours. The incorporation of deuterium in Llysine using RuPt-nor, RuPt-DMC, RuPt-dba and $\mathbf{R u P t}_{2}$-dba NPs as catalyst is generally lower than with Ru NPs (Table 1 and Figures S27-32). ${ }^{8 c}$ The $\alpha$ and $\varepsilon$ positions of L-lysine were nearly completely deuterated using RuPt-nor, RuPt-DMC and RuPt-dba, but using $\mathbf{R u P t}_{2}$-dba the activity decreased considerably. The latter result was expected because Pt is not active in this catalytic reaction and $\mathbf{R u P t}_{2}$-dba present higher Pt content. We also observed a change in selectivity using the RuPt bimetallic NPs since we did not detect any deuteration on the $\gamma$ position of lysine in contrast to monometallic Ru NPs. Thus, the presence of Pt at the NP surface inhibits the H/D exchange in $\gamma$ position, in addition to reducing the activity of the catalyst.

Table 1. Deuteration experiments with L-lysine. ${ }^{[a]}$

\begin{tabular}{|c|c|c|c|c|c|}
\hline Catalyst & $\alpha(\%)$ & $\beta(\%)$ & $\gamma(\%)$ & $\delta(\%)$ & $\varepsilon(\%)$ \\
\hline $\mathbf{R} \mathbf{u}^{8 c}$ & 99 & 0 & 12.5 & 0 & 98.5 \\
\hline RuPt-nor & 94 & 0 & 0 & 0 & 96 \\
\hline RuPt-DMC & 97 & 0 & 0 & 0 & 97.5 \\
\hline RuPt-dba & 91 & 0 & 0 & 0 & 97 \\
\hline $\mathrm{RuPt}_{2}$-dba & 69 & 0 & 0 & 0 & 67 \\
\hline $\mathbf{P t}$ & 6 & 0 & 3.5 & 0 & 0 \\
\hline
\end{tabular}

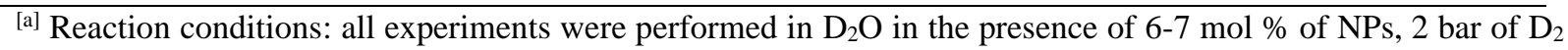
at $55^{\circ} \mathrm{C}$ during $42 \mathrm{~h}$.

In order to compare more precisely the activity of the different systems, kinetic studies were carried out. For this purpose, $\mathrm{D}_{2} \mathrm{O}$ solutions of $1 \mathrm{mg} / \mathrm{mL}$ of NPs with $11 \mathrm{mg}$ of L-lysine where heated at $55^{\circ} \mathrm{C}$ 
during $16 \mathrm{~h}$ in a high pressure NMR tube under 2 bars of $\mathrm{D}_{2}$, and deuterium incorporation in L-lysine was monitored by ${ }^{1} \mathrm{H}$ NMR spectroscopy (Figure 5). As observed in the previous catalytic experiments, the highest conversion was achieved with Ru. However, interestingly, bimetallic systems RuPt-nor and RuPt-DMC showed a faster reaction rate during the initial 3 hours. After this time, we observed a radical change in the deuteration rate, probably due to some deactivation processes or reorganization of the NP surface. On the other hand, as predictable, $\mathbf{R u P t}_{2}$-dba presented the lowest activity, because of its high Pt content.
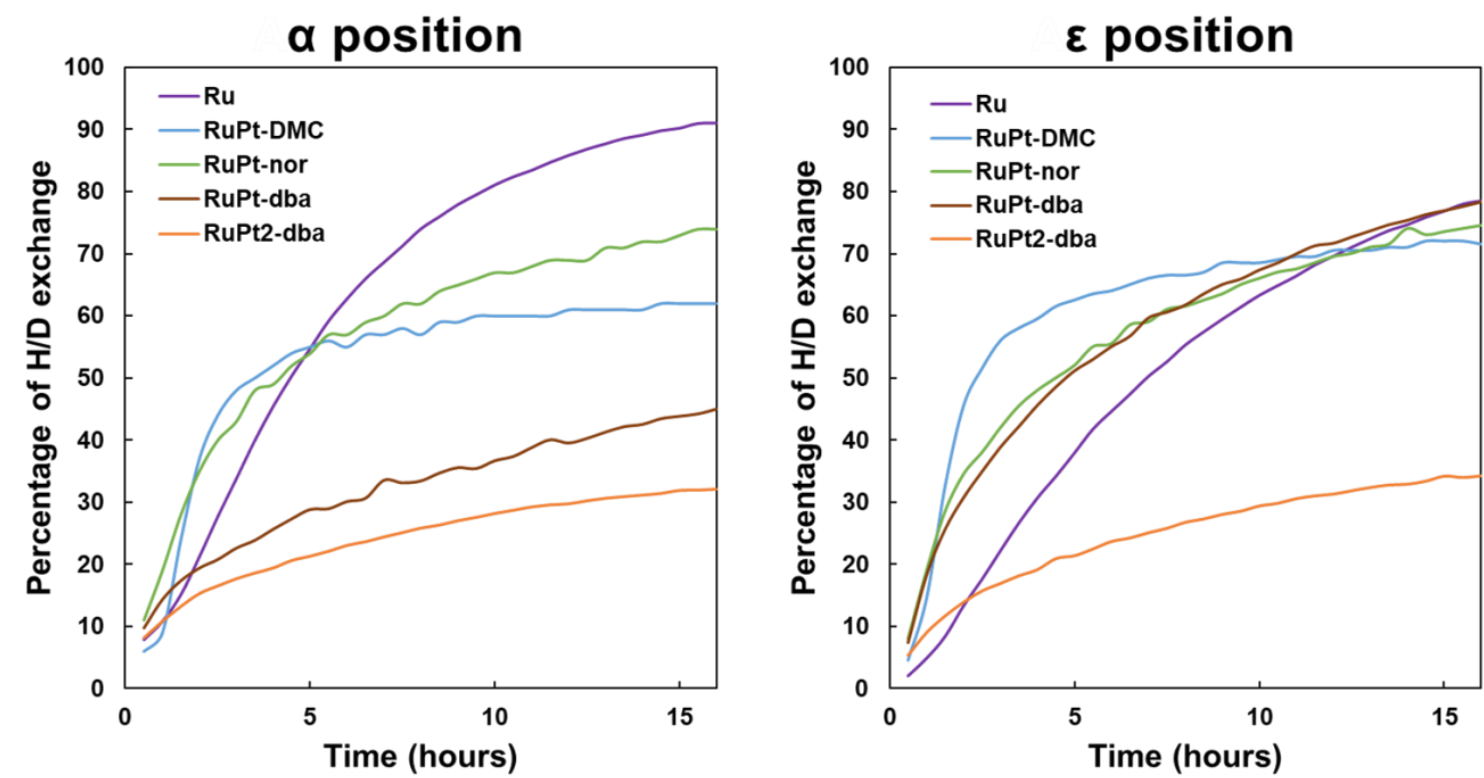

Figure 5. Activities of Ru, RuPt-nor, RuPt-DMC, RuPt-dba and $\mathbf{R u P t}_{2}-\mathbf{d b a}$ for C-H deuteration of L-lysine as a function of the time on the $\alpha$ (left) and $\varepsilon$ position (right).

In terms of selectivity, the monometallic Ru catalyst deuterates faster the $\alpha$ position than the $\varepsilon$ one because of the lower pKa of the $\alpha$-ammonium ion $[\mathrm{pKa}(\alpha)=8.95 ; \mathrm{pKa}(\varepsilon)=10.53]$. To have an effective H/D exchange, the amino groups of the L-lysine have to coordinate to the Ru surface in the $\mathrm{NH}_{2}$ form. And, at the catalytic conditions there are only $42 \%$ of amino groups in $\varepsilon$ position, in contrast to $98 \%$ in $\alpha$ position. ${ }^{8 c}$ However, surprisingly, RuPt-DMC and RuPt-dba showed the opposite selectivity in the same catalytic conditions at similar $\mathrm{pH}$ value, with a slower deuteration of the $\alpha$ position compared to the $\varepsilon$ one. The presence of Pt at the NP surface decreases the rate of the reaction at the $\alpha$ position. RuPt-nor is less affected as it presents Ru-rich zones at the NP surface (RuPt-DMC shows beginning of segregation but enriched in Pt, and RuPt-dba shows an alloyed phase). However, deuteration at the $\varepsilon$ position remains almost unchanged for NPs with Ru:Pt ratios equal to 1:1. Increasing the Ru:Pt ratio to $1: 2$ then significantly decreases the H/D exchange efficiency at any position. 


\section{Chemical shift perturbation.}

To gain insight into the differential reactivity of the Ru or mixed RuPt NPs, and notably the preferential deuteration of the $\varepsilon$ rather than the $\alpha$ position, we recorded NMR spectra of Lysine samples at different concentrations in the presence of Ru or RuPt-dba NPs, which show the more pronounced decrease of deuteration at the $\alpha$ position. In order to correct the $\mathrm{pH}$ variations of these unbuffered samples, we added $0.5 \mathrm{mM}$ of trimethylsilylpropanoic acid (TMSP) and of $\mathrm{Na}_{2} \mathrm{HPO}_{4}$ before lyophilizing the individual samples and we carefully adjusted the $\mathrm{pH}$ to a value of $9.22 \pm 0.02$ before adding the NPs. Referencing of the proton spectra thereby becomes easier, and the ${ }^{31} \mathrm{P}$ NMR signal of the phosphate buffer allows verifying the $\mathrm{pH}$ of the final sample in a non-intrusive manner (Figure S33). ${ }^{20}$

Similarly as reported before, chemical shift perturbations (CSPs) upon increasing the NP/Lysine ratio were more pronounced in the proton than in the carbon dimension for the ${ }^{1} \mathrm{H},{ }^{13} \mathrm{C}$ correlations corresponding to the $\alpha$ and $\varepsilon$ positions, whereas the inverse was true for the $\beta$ position (Figure S34). In order to see more subtle differences between both series, we recorded high resolution proton 1D spectra. Reference spectra of the lysine samples at different concentrations but without NPs gave an idea about the precision of the measurement, and indicated that variations higher than $5 \mathrm{~Hz}$ could be considered as significant (Figure S34). For Ru NPs, the CSP values are $17 \mathrm{~Hz}$ for the $\mathrm{H} \alpha$ proton but only $9 \mathrm{~Hz}$ for the $\mathrm{H} \varepsilon$ upon tenfold variation of the Lysine concentration (Figure 6). The pKa of the side chain amino group being further away from the actual $\mathrm{pH}$, this behaviour correlates well with the preferential deuteration at the $\alpha$ rather than the $\varepsilon$ position. For the RuPt NPs, we found an even larger value of $25 \mathrm{~Hz}$ for the $\mathrm{H} \alpha \mathrm{CSP}$, whereas a value of $8 \mathrm{~Hz}$ was observed for the $\mathrm{H} \varepsilon$. In contrast to the $\mathrm{Ru}$ NPs, where observation of the absorbed $\mathrm{CO}$ led to the picture of a readily accessible surface, composed of $\mathrm{Ru}(0)$ and well-dispersed NHC ligands, the RuPt NPs contain both Ru and Pt atoms at their surface next to the same ligands. The comparable CSP for the He protons suggests that they approach the surface of both Ru and RuPt NPs in a similar fashion, and hence rather coordinate to the $\mathrm{Ru}$ atoms. Comparable CSP for the $\mathrm{H} \varepsilon$ protons is in good agreement with comparable deuteration during the kinetics study. In contrast, the differential CSP for the $\mathrm{H} \alpha$ protons hints to a different environment for the $\mathrm{H} \alpha$ proton when approaching the RuPt NP rather than the Ru NP. The possibility of a chelating effect involving both the amine and the acid groups can thus enhance the coordination of the Lysine to the RuPt surface and thus a strong adsorption of the groups close to the $\mathrm{C} \alpha$. As predicted by the Sabatier principle, the stronger coordination of the carboxylate in presence of Pt leads to a decrease of the catalytic efficiency. ${ }^{21}$ As the interaction between the substrate and the surface is

\footnotetext{
${ }^{20}$ N. Cox, R. Kuemmerle, P. Millard, E. Cahoreau, J. M. François, J. L. Parrou, G. Lippens Anal. Chem. 2019, 91, 3959.

${ }^{21}$ L. Cusinato, I. del Rosal, R. Poteau, Dalton Trans. 2017, 46, 378.
} 
stronger, the product fails to dissociate rapidly from the NPs, thereby decreasing the overall efficiency of this reaction at this position.

a)

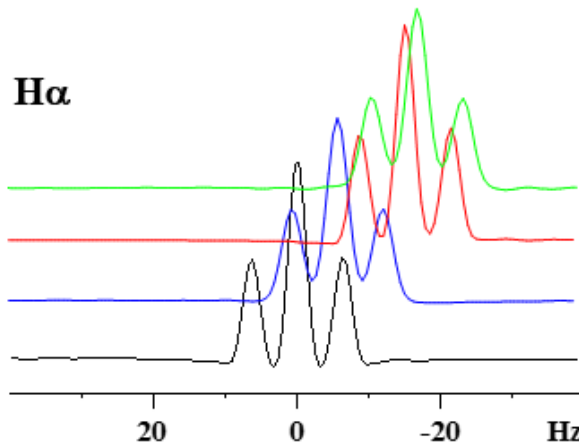

b)
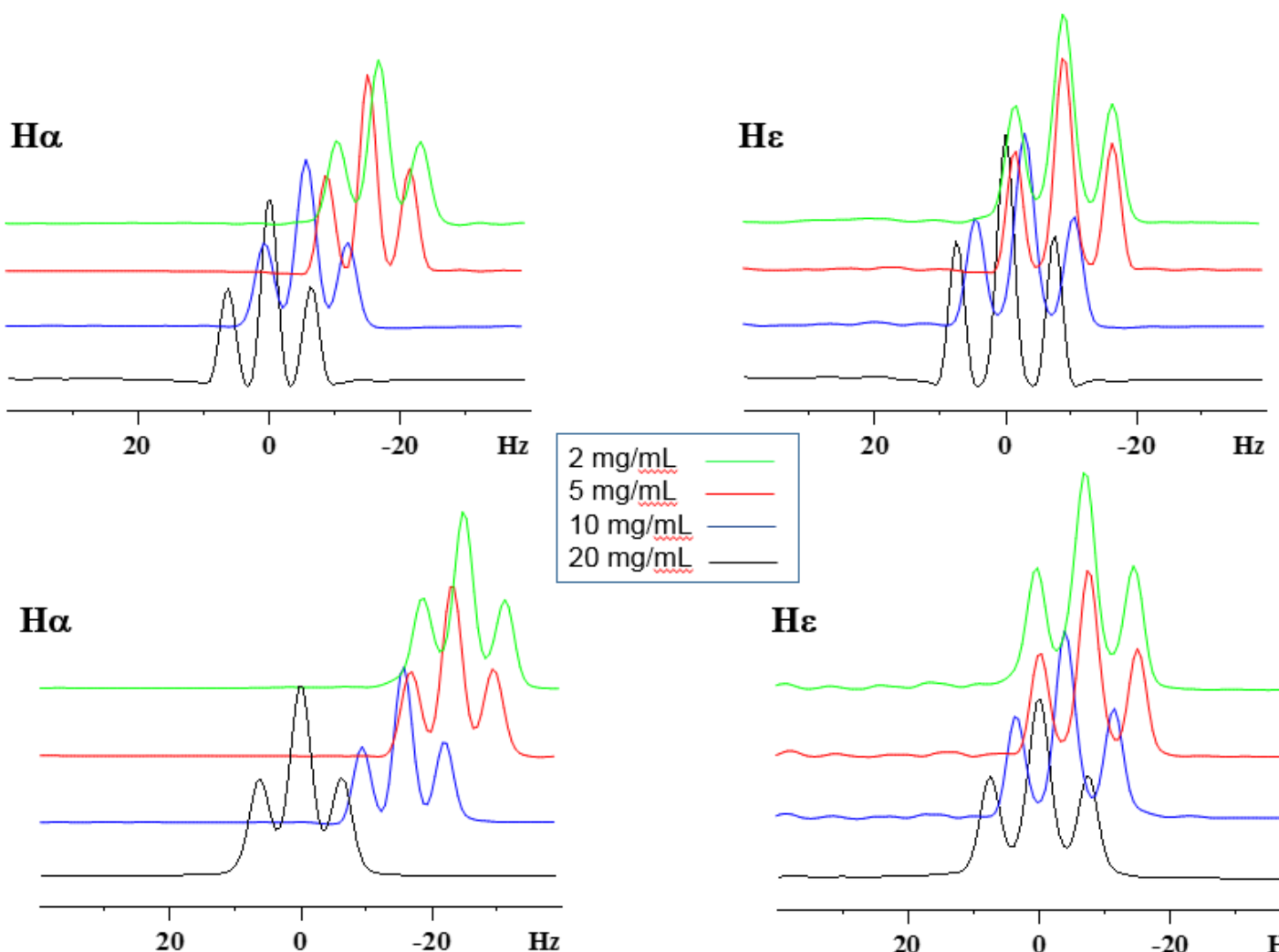

$\mathrm{H} \varepsilon$

Figure 6. Chemical Shift Perturbation measurements in high resolution proton 1D spectra for Ru (a) and RuPt-dba (b) on the L-lysine ( $\mathrm{C} \alpha$ and $\mathrm{C} \varepsilon$ positions), decreasing the concentration of lysine, at constant concentration of NPs.

\section{Conclusion}

This study shows that the organometallic methodology previously used to prepare monometallic Ru or Pt carbene-stabilized NPs can be easily extended to bimetallic NPs and that the surface of the NPs can be tuned according to the precursors used as evidenced by a combination of structural and spectroscopic studies. Then, the exchange of Ru atoms by Pt at the NP surface led to a regioselective decrease of reactivity in H-D exchange at the $\mathrm{C} \alpha$ position of L-lysine, whereas no significant modification in reactivity was observed at the $\mathrm{C} \varepsilon$ position. Such a behaviour can be explained by a chelating effect due to the presence of Pt, which probably interacts with the carboxylic acid group of L-lysine, close to the C $\alpha$. The concentration of Pt at the NP surface thus plays an important role in the selectivity of the C-H activation process. Comparing the selectivity of RuPt-nor and RuPt-DMC, with different surface compositions, we observe that RuPt-nor shows the smaller decrease in reactivity at the $\mathrm{C} \alpha$ position, whereas RuPt-DMC shows a more pronounced decrease. The higher surface concentration of Pt in RuPt-DMC than in RuPt-nor thus favours the selectivity at the $\varepsilon$ position. Finally, WAXS and solid state NMR measurements suggest that RuPt-dba is an alloy, 
without any phase segregation, and FT-IR measurements shows similar surface enrichment in Ru as for RuPt-nor. RuPt-dba low catalytic reactivity in the $\mathrm{C} \alpha$ position can be attributed to the regular dispersion of $\mathrm{Pt}$ atoms at the NP surface, and thus to the absence of more reactive isolated areas enriched in $\mathrm{Ru}$. In addition, the presence of a dynamic surface, modified as a function of the present ligands, cannot be excluded, as previously observed in PdCu NPs. ${ }^{22}$ In summary, we have shown that the chemical composition of the surface of RuPt NPs can be tuned, either by the ratios of the precursors, or by their relative decomposition rates. The use of sulfonated NHCs gave the opportunity to obtain water-soluble NPs, stable for months. The synthesis of bimetallic NPs by decomposition of organometallic precursors is thus a powerful approach to control the surface reactivity of metallic nanoparticles, notably in the context of selective $\mathrm{C}-\mathrm{H}$ activation processes.

\section{Conflicts of interest}

There are no conflicts of interest to declare.

\section{Acknowledgements}

Donia Bouzouita is participant to the EU ISOTOPICS consortium. The ISOTOPICS project has received funding from the European Union's Horizon 2020 research and innovation programme under the Marie Sklodowska-Curie grant agreement $\mathrm{N}^{\circ} 675071$. We thank Pr. Romuald Poteau for rewarding discussions, Simon Cayez for SEM-EDX analysis, Christian Bijani for NMR mesasurements and UMS-Castaing for TEM facilities.

22 J.S. Bradley, E.W.Hill, B.Chaudret, A.Duteil. Langmuir, 1995, 11, 693. 